\title{
Comparative Study of the Effects of Salinity on Plant Growth, Nodu- lation, and Legheamoglobin Content in Kabuli and Desi Cultivars of Cicer arietinum (L.)
}

\author{
Varsha Mudgal ${ }^{*}$, Nidhi Madaan', Anurag Mudgal' ${ }^{2}$ Alka Singh $^{3}$, P. Kumar ${ }^{3}$
}

${ }^{1}$ Department of Biotechnology; ${ }^{2}$ Department of Mechanical Engineering College of Engineering and Technology, IFTM Campus, Moradabad, UP, India; ${ }^{3}$ Department of Botany, Hindu College, Moradabad, UP, India

Received: December 19, 2009 / Accepted: February 27, 2010

\section{Abstract}

$\mathbf{T}$ his study was conducted to compare plant growth, nodulation and legheamoglobin content in Kabuli and Desi cultivars of chickpea (Cicer arietinum (L.)) under saline conditions. All the varieties expressed greater adverse effects on the plant height, dry weight of shoot and root at 30 and 60 DAS whereas the deleterious effects of the salinity minimized at 90 DAS. It is evident that variety BG-256 registered maximum inhibition at all the three growth stages (30,60 and 90 DAS) as compared to varieties PUSA-939 and PUSA-1053. Relative growth rate (RGR) is high in PUSA-1053 (Kabuli tolerant), stands midway in PUSA-939 (Kabuli moderate tolerant) and is low in BG-256 (Desi sensitive). Maximum nodulation was reported in variety PUSA-1053 at all the growth stages and all salinity levels (4- $16 \mathrm{EC}$ ) while minimum nodulation occurred in variety BG-256. The data clearly indicate that legheamoglobin content of the nodules increased at 60 DAS and declined thereafter. Kabuli tolerant variety (PUSA-1053) showed highest and Desi sensitive (BG256) showed least legheamoglobin content at all the salinity levels from 4-16 EC and at all the growth stages from 30-90 DAS. The dry weigh of shoot and number of nodules were affected more adversely than nodule dry weight and legheamoglobin content. It indicates that Kabuli cultivars are more tolerant to saline stress and show less deleterious effects on nodules and nitrogen fixation efficiency.

Key Words: Cultivar, salinity, EC (electrical conductivity), leghaemoglobin, DAS (days after sowing), nodulation.

\footnotetext{
* Corresponding author: varsha.mudgal@gmail.com
}

\section{Introduction}

Salinity produces harmful effects on plant growth and yield. Permanent and complementary solution to minimize the deleterious effects of the salinity is to select and grow cultivars that can provide economic yield under saline conditions. Among legume crops, Chickpea ranks first in terms of area and production. It provides a high quality protein to the people of developing countries. It is usually grown mixed with wheat, barley, linseed and mustard. Selected cultivars of chickpea are Desi type with small and brown seed (nearly 90\% area) and Kabuli type with bold and cream-colored seed (growing in 10\% area). Desi chickpeas have markedly higher fiber content and lack pigmentation than Kabulis and hence a very low glycemic index which may make them suitable for people with high blood sugar problems. Kabuli Genotype show higher tolerance to salinity (Rao et al., 1995; Soussci et al., 1998). The present study compares Kabuli and Desi genotypes of chickpea in terms of growth, physiological and biochemical markers of salt tolerance. It will be helpful to select of chickpea varieties with improved salt tolerance for sustaining food production.

\section{Materials and Methods}

To assess the effect of saline water irrigation on chickpea, a field experiment was conducted in year 2007-2008. Plots of $1 \times 1 \mathrm{~m}^{2}$ area were prepared and separated from each other by polythene sheets of $0.2 \mathrm{~mm}$ thickness, up to depth of $30 \mathrm{~cm}$ to stop leaching of salts between two adjacent plots. Plant to plant distance was $15 \mathrm{~cm}$ and plots were separated by a distance of $45 \mathrm{~cm}$. The experiment was laid out in randomized bloke design with six replicates. Tubewell water of $1 \mathrm{dsm}^{-1} \mathrm{EC}$ was used to irrigate control sets. Saline solutions of 4, 8, 12, and 16 EC were prepared by mixing the salts $\mathrm{NaCl}, \mathrm{Na}_{2} \mathrm{SO}_{4}, \mathrm{NaHCO}_{3}$ and $\mathrm{CaCl}_{2}$. Three selected varieties PUSA-1053 (tolerant Kabuli), PUSA-939 (moderately sensitive Kabuli) and BG-256 (sensitive Desi) were grown in the experimental plots. Study the effect of 
saline water irrigation on plant growth, nodulation, and legheamoglobin content at different growth stages. Saline water of $4,8,12$ and $16 \mathrm{dsm}^{-1}$ EC used to irrigate the plants at 20, 50 and 70 days after sowing (DAS). First sample of plants were collected at 30 DAS. Plant height, root and shoot length were recorded at 30 DAS. Root, shoot and leaves were dried in hot oven at $60^{\circ} \mathrm{C}$ for 48 hours and then dry weight of each were recorded. Same exercise was repeated at 60 and 90 DAS.

Relative growth rate (RGR) calculated as:

$$
R G R=\left(D M_{2}-D M_{1}\right)\left(t_{2}-t_{1}\right)^{-1}\left(g-g \times d^{-1}\right)
$$

Where $D M_{1}=$ initial total (shoot + root) dry mass, $D M_{2}=$ final total dry mass, and $\left(t_{2}-t_{1}\right)=$ time difference between two samplings (30 d).

At each stage number of nodules were counted and separated from the root. Detached nodules were then dried in hot oven at $60^{\circ} \mathrm{C}$ for 48 hours and dry weight was recorded. Afterwards this dried material was used for estimation of legheamoglobin

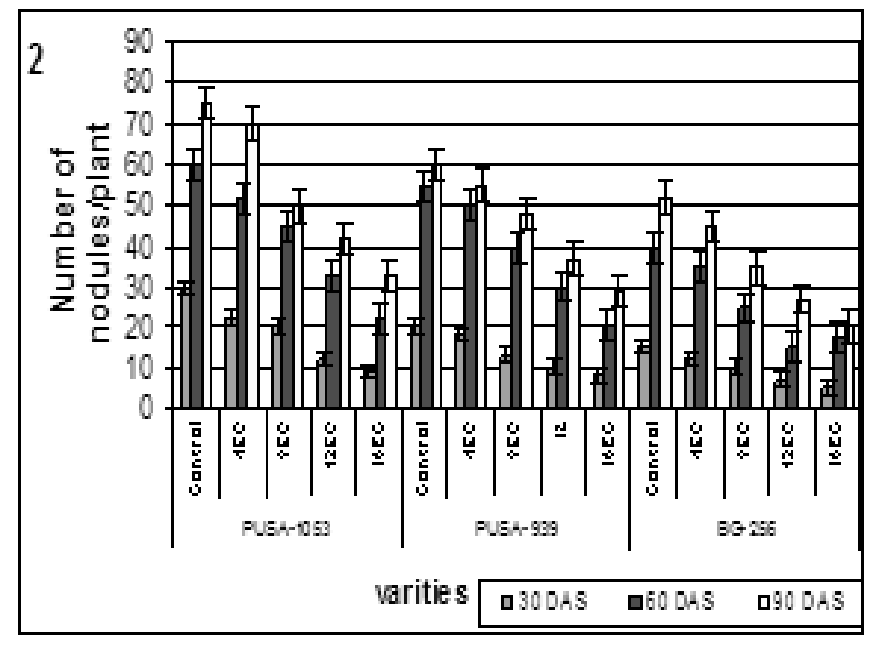

Fig. 2. Effect of salinity on number of nodules/plant in three chickpea cultivars at 30,60 and 90 DAS.

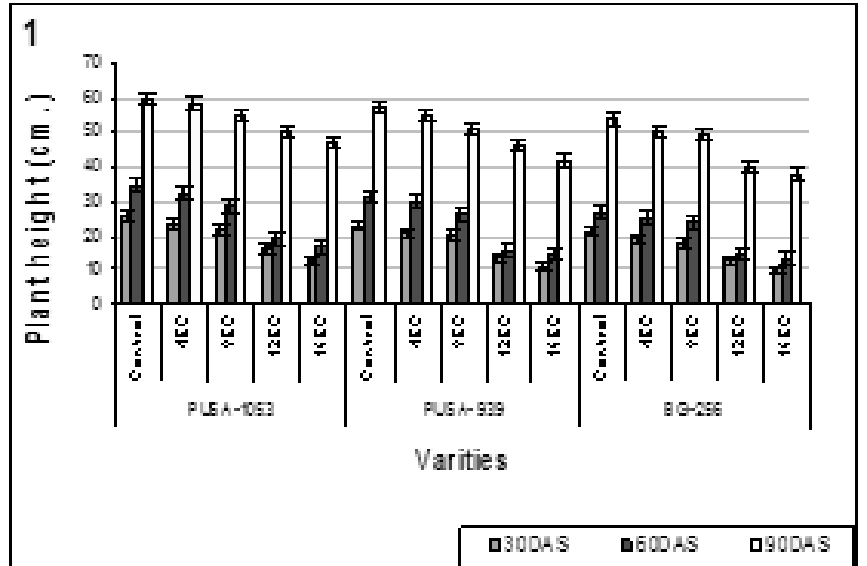

Fig. 1. Effect of salinity on plant height $(\mathrm{cm})$ of three chickpea cultivars at 30,60 and 90 DAS.

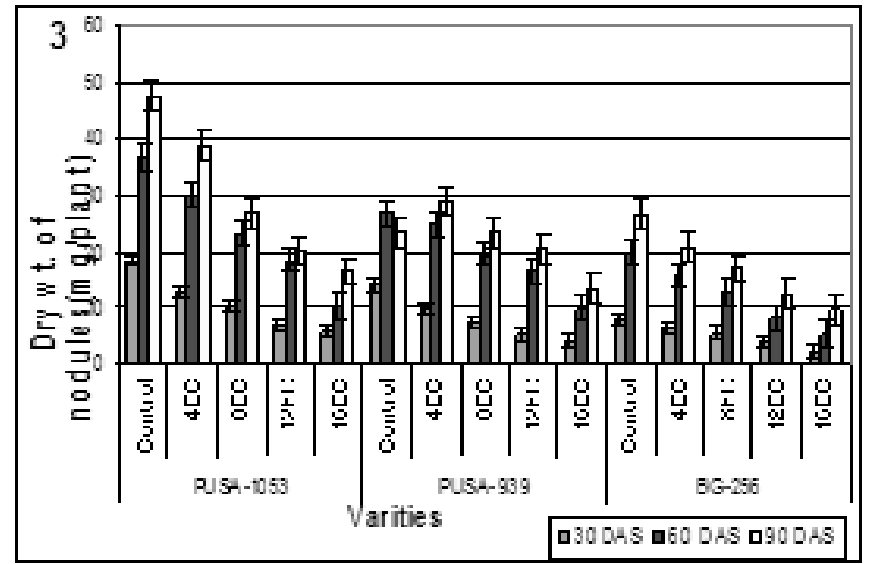

Fig. 3. Effect of salinity on dry weight of nodules/Plant in three chickpea cultivars at 30,60 and 90 DAS (data are expressed in $\mathrm{mg} /$ plant).

Table 1. Effect of saline water irrigation on Relative growth rate (RGR) in three cultivars of Cicer arietinum $L$ with the help of Dry weight of root (DWR) and Dry weight of shoot (DWS) after 30 and 60 Days after sowing (DAS).

\begin{tabular}{|c|c|c|c|c|c|c|c|c|c|}
\hline \multirow[t]{2}{*}{ Variety } & \multirow{2}{*}{$\begin{array}{l}\text { EC of Water } \\
\text { dsm }\end{array}$} & \multicolumn{2}{|c|}{ DWR (mg) } & \multicolumn{2}{|c|}{ DWS (mg) } & \multirow[t]{2}{*}{ DM1 } & \multirow[t]{2}{*}{ DM2 } & \multirow[t]{2}{*}{ DM2-DM 1} & \multirow[t]{2}{*}{ RGR } \\
\hline & & 30DAS & 60DAS & 30DAS & 60DAS & & & & \\
\hline \multirow[t]{5}{*}{ PUSA-1053 } & 0 & $63.1( \pm 4.33)$ & $75( \pm 5.22)$ & $430( \pm 4.25)$ & $535( \pm 4.33)$ & 493.1 & 610 & 116.9 & 3507 \\
\hline & 4 & $60( \pm 3.32)$ & $65.6( \pm 3.43)$ & $300( \pm 3.27)$ & $350( \pm 2.45)$ & 360 & 415 & 55.6 & 1168 \\
\hline & 8 & $55( \pm 4.33)$ & $58( \pm 2.25)$ & $275( \pm 3.25)$ & $320( \pm 4.53)$ & 330 & 378 & 48 & 1440 \\
\hline & 12 & $40( \pm 4.21)$ & $50( \pm 2.45)$ & $210( \pm 4.33)$ & $240( \pm 3.54)$ & 250 & 290 & 40 & 1200 \\
\hline & 16 & $35( \pm 3.35)$ & $45( \pm 3.25)$ & $195( \pm 4.53)$ & $220( \pm 3.35)$ & 230 & 265 & 45 & 1050 \\
\hline \multirow[t]{5}{*}{ PUSA-939 } & 0 & $52( \pm 3.26)$ & $72( \pm 3.54)$ & $300( \pm 4.37)$ & $400( \pm 3.28)$ & 372 & 472 & 100 & 3000 \\
\hline & 4 & $50( \pm 4.25)$ & $60( \pm 3.53)$ & $260( \pm 4.33)$ & $310( \pm 3.27)$ & 316 & 370 & 54 & 1620 \\
\hline & 8 & $35( \pm 3.35)$ & $40( \pm 3.43)$ & $240( \pm 3.26)$ & $280( \pm 4.21)$ & 275 & 320 & 45 & 1350 \\
\hline & 12 & $27( \pm 5.55)$ & $30( \pm 3.44)$ & $180( \pm 3.28)$ & $215( \pm 3.27)$ & 207 & 245 & 38 & 1190 \\
\hline & 16 & $27( \pm 3.27)$ & $35( \pm 3.28)$ & $130( \pm 3.26)$ & $160( \pm 5.55)$ & 157 & 195 & 32 & 960 \\
\hline \multirow[t]{5}{*}{ BG-256 } & 0 & $50( \pm 3.33)$ & $68( \pm 3.13)$ & $72( \pm 3.54)$ & $320( \pm 3.38)$ & 308 & 388 & 80 & 2400 \\
\hline & 4 & $36( \pm 3.44)$ & $40( \pm 3.38)$ & $60( \pm 3.53)$ & $278( \pm 3.26)$ & 278 & 318 & 40 & 1200 \\
\hline & 8 & $28( \pm 3.67)$ & $45.6( \pm 4.25)$ & $180( \pm 2.25)$ & $280( \pm 3.25)$ & 208 & 325.6 & 35 & 1050 \\
\hline & 12 & $20.2( \pm 3.74)$ & $38.7( \pm 3.26)$ & $150( \pm 3.38)$ & $250( \pm 3.53)$ & 170.2 & 288.7 & 30 & 900 \\
\hline & 16 & $18.3( \pm 3.77)$ & $25.1( \pm 4.47)$ & $100( \pm 3.33)$ & $220( \pm 4.25)$ & 118.3 & 245.1 & 20 & 600 \\
\hline
\end{tabular}


Table 2. Effect of salinity on leghaemoglobin content of nodules in Cicer arietinum L. at 30,60 and 90 DAS (data are expressed in mg/gm fresh wt. of nodules).

\begin{tabular}{lllll}
\hline Variety & EC of Water $\left(\mathbf{d s m}^{-1}\right)$ & \multicolumn{3}{l}{ Days after sowing } \\
\cline { 3 - 5 } & & 30 DAS & 60 DAS & 90 DAS \\
\hline PUSA-1053 & Control & $57( \pm 3.27)$ & $93( \pm 3.53)$ & $58( \pm 4.25)$ \\
& 4 & $47( \pm 2.25)$ & $76( \pm 4.25)$ & $45( \pm 3.44)$ \\
& 8 & $38( \pm 4.25)$ & $64( \pm 4.21)$ & $43( \pm 3.35)$ \\
& 12 & $20( \pm 3.26)$ & $58( \pm 3.13)$ & $35( \pm 3.43)$ \\
PUSA-939 & 16 & $11( \pm 4.25)$ & $47( \pm 3.74)$ & $24( \pm 3.13)$ \\
& Control & $54( \pm 3.25)$ & $91( \pm 4.21)$ & $72( \pm 3.53)$ \\
& 4 & $43( \pm 3.54)$ & $74( \pm 4.67)$ & $40( \pm 2.53)$ \\
& 8 & $34( \pm 3.45)$ & $60( \pm 4.56)$ & $35( \pm 3.54)$ \\
BG-256 & 12 & $16( \pm 4.54)$ & $55( \pm 3.53)$ & $27( \pm 4.21)$ \\
& 16 & $8( \pm 5.13)$ & $45( \pm 3.52)$ & $20( \pm 3.58)$ \\
& Control & $50( \pm 4.53)$ & $88( \pm 2.21)$ & $62( \pm 2.25)$ \\
& 4 & $48( \pm 3.53)$ & $70( \pm 2.26)$ & $30( \pm 2.36)$ \\
& 8 & $30( \pm 4.24)$ & $54( \pm 2.21)$ & $25( \pm 4.33)$ \\
& 12 & $14( \pm 3.21)$ & $47( \pm 3.27)$ & $21( \pm 3.46)$ \\
& 16 & $4( \pm 4.34)$ & $38( \pm 4.21)$ & $11( \pm 2.27)$ \\
\hline
\end{tabular}

content of the nodules. For the sake of convenience and accuracy all the above observations were taken in six replicates and each replica carried ten plants. For the estimation of legheamoglobin nodules were picked up at 30,60 and 90 DAS. Nodules were carefully picked up from the roots and thoroughly washed with prechilled double distilled water. After washing nodules, blotted on the filter paper, weighed and finally crushed in prechilled sterilized mortar-pestle containing $50 \mathrm{mM} \mathrm{HCl}, 5 \mathrm{mM} \mathrm{MgCl} 2,20$ $\mathrm{mM} \mathrm{KCl}, 5 \mathrm{mM}$ - mercapto ethanol. The slurry was centrifuged at $40 \mathrm{C}$ at $8,000 \mathrm{xg}$ for 15 minutes. The pellets were discarded and Supernatant (SN) was made to a known volume i.e. $4 \mathrm{ml} /$ $\mathrm{gm}$ fresh weight of nodules. In this Supernatant, legheamoglobin content was estimated by using hemochromogen method with a slight modification. Legheamoglobin contents are expressed as $\mathrm{mg}$ heamin/ $\mathrm{gm}$ fresh weight of nodules.

\section{Results and Discussion}

Salinity retards the plant growth from germination to maturity. This retardation is due to an increase in the osmotic pressure of the root medium and/or by the specific ion effects or the combination of both. The effect of salinity on plant height is shown in (Figure 1).

Effect of salinity on relative growth rate summarized with the help of dry weight of shoot and dry weight of root, there is a significant reduction in the overall growth of plants irrespective of the type of cultivar. This was evident from the decline in relative growth rate with increasing stress (Table 1). The smallest reduction was seen in PUSA-1053 (Kabuli) and the largest in BG-256 (Desi). The decline in root dry mass is probably due to the reduction of nutrients transport from soil to the growing shoots. Therefore, a decrease in shoot dry matter accompanied by a decline in root dry matter is expected. We compared the response of chickpea varieties to salinity and we found that there was about 50\% reduction in shoot growth at $16 \mathrm{EC}$ as compared to control. Root and shoot mass reduction in response to salinity has been reported earlier for desi chickpea (Elsheikh and Wood, 1990). Similar reduction in crop growth has earlier been reported in barley, mung bean, chick pea and soybean (Garg, 2004; Mudgal, 2004; Rao et al., 2002; Zurayk et al., 1998). In Kabuli tolerant variety (PUSA-1053) shoot appear to be more sensitive to salinity than roots even at low salinity levels but in sensitive variety PUSA-939 and BG-256 roots are more sensitive. Cultivar BG-256 was adversely affected at all stages as compared to PUSA-1053 and PUSA-939.

The effect of salinity on the number and dry weight of nodules/plant at three durations (30,60, 90 DAS) at 0, 4, 8, 12 and $16 \mathrm{dsm}-1$ salinity levels are shown in (Figure 2) and (Figure 3), respectively. Salinity delayed the onset of nitrogen fixation and prevented nitrogen fixation from resulting in significant growth but did not eliminate nodulations or the supply of nitrogen from nodule to shoot. Subbaroa et al. (1990) also reported that of the 4 strains effective under control only 2 were effective under salinity. In variety PUSA-1053 at 60 DAS had 60 nodule/ plant in control sets and the number decreased to 22 nodules/ plant at $16 \mathrm{dsm}-1$. The weight of nodules/plant was significantly decreased by salinity 30 days after sowing PUSA-1053 shows (68\%), PUSA-939 (70\%) and BG-256 (73\%) reduction in weight of nodules/plant at highest salinity level as compared to control.

The failure of nodule formation at high salinity might be attributed to shrinkage of root hairs; consequently the reduction in plant growth under conditions of high salinity could only be partly accounted by the reduction or failure in nodulation (Tu, 1981; Mudgal et al., 2009). Zahran (1999) also showed that $\mathrm{NaCl}$ affected infection and nodulation. Dry weight of nodules is affected less adversely than its number.

Effect of salinity on leghaemoglobin content of nodules in three varieties of chickpea at 30,60 and 90 DAS is given in (Table 2). It is evident from the data that leghaemoglobin content of the nodules decreased when the levels of salinity increase, however varietal differences were evident. In all varieties maximum legheamoglobin content was observed at 60 DAG, which decreased thereafter due to aging and irreversible oxidation of legheamoglobin, also observed by Siddiqui et al. (1985) in 
pea nodules. In the early intracellular infection stage characteristic nitrogenase and legheamoglobin are absent or inactive. In the mature stage nitrogen fixation activity and legheamoglobin concentration become high. Sheokand et al. (1995) observed that $\mathrm{NaCl}$ treatment of the plants accelerated nodule greening, accompanied by a concomitant decrease in leghemoglobin (Lb) content of the nodules. With $50 \mathrm{mM} \mathrm{NaCl}$, increase in duration of the treatment from 7 to 14 days, the Lb content recovered by $15 \%$ (rising from $41 \%$ to $56 \%$ of the control). However, under $\mathrm{NaCl} 100 \mathrm{mM}$ treatment $\mathrm{Lb}$ content declined further dropping from $27 \%$ to $18 \%$ of the control 14 days after treatment (DAT). Babber et.al.( 2000) reported that leghemoglobin content of control plants decreased by $50 \%$ at day 85 indicating senescence of nodules. This senescence was further accelerated by salt treatment after which the leghemoglobin content fell to negligible levels. The structural changes associated with salt stress were mainly reduction in size of the nodules, decreased meristematic zone, reduced number and degradation of symbiosomes, reduced intercellalar spaces and deposition of electron dense material in the intercellular spaces in the cortex of nodules.intercellalar spaces and deposition of electron dense material in the intercellular spaces in the cortex of nodules.

\section{References}

Babber S, S Sheokand, and S Malik (2000) Nodule Structure and Functioning in Chickpea (Cicer arietinum) as Affected by Salt Stress. Biologia Plantarum. 43(2): 269-273.

Elsheikh EAE, and M Wood (1990) Effect of Salinity on Growth, Nodulation and Nitrogen Yield of Chickpea (Cicer arietinum L.). J Exp Bot
41: 1263-1269.

Garg N, R Singla (2004) Growth, photosynthesis, nodule nitrogen and carbon fixation in the chickpea cultivars under salt stress. Braz J Plant Physiol 16(3): 137-146.

Mudgal V (2004) Physiological Studies on Growth and Nitrogen Metabolism in Cicer arietinum L. Under Saline Conditions. PhD Dissertation, Rohilkhand University, India.

Mudgal V, N Madaan, A Mudgal, and S Mishra (2009) Changes in growth and metabolic profile of Chickpea under salt stress. J Appl Biosci 23: 1436-1446.

Rao DLN, and PC Sharma (1995) Alleviation of salinity stress in chickpea by Rhizobium inoculation or nitrate supply. Biologia Plantarum 37(3): 405-410.

Rao DL, N Giller, KE Yeo, and TJ Flowers (2002) The Effects of Salinity and Sodicity upon Nodulation and Nitrogen Fixation in Chickpea (Cicer arietinum) Annals of Botany 89: 563-570.

Sheokand S, S Dhandi, and K Swaraj (1995) Studies on nodule functioning and hydrogen peroxide scavenging enzymes under salt stress in chickpea nodules. Plant Physiology and Biochemistry 33: 561-566.

Siddiqui S, and S Kumar (1985) Indian J Plant Physiol 28(2): 151-156.

Soussci MQ, A Ocana, and C Lluch (1998) Effects of salt stress on growth, photosynthesis and nitrogen fixation in chick-pea (Cicer arietinum (L.)). J Exp Bot 49(325): 1329-1337.

Subbaroa GV, C Johansen, MK Jona, R Kumar, and JV D.K. (1991) Comparative Salinity Responses among Pigeonpea Genotypes and Their Wild Relatives. Crop Sci 31: 415-418.

Tu JC (1981) Effect of salinity on Rhizobium-root hair interaction, nodulation and growth of soybean. Can J Plant Sci 61: 231-239.

Zahran HH (1999) Rhizobium-Legume Symbiosis and Nitrogen Fixation under Severe Conditions and in an Arid Climate. Microbiology and Molecular Biology Reviews 63(4): 968-989.

Zurayk R, M Adian, R Baalbaki, and MC Saxena (1998) Interactive Effects of Salinity and Biological Nitrogen Fixation on Chickpea (Cicer arietinum (L.)) Growth. J Agron Crop Sci 180 (4): 249-258. 